\section{GREGORY VLASTOS Y LOS ESTUDIOS SOBRE EL SÓCRATES HISTÓRICO*}

\section{Carmen Trueba Atienza**}

RESUMO: Este artigo discute a abordagem de Sócrates por Gregory Vlastos em "The historical Socrates and Athenian Democracy", trabalho publicado na revista Political Theory (1983), e sua repercussão.

PALAVRAS-CHAVE: Gregory Vlastos; Sócrates; democracia grega.

GREGORY VLASTOS AND STUDIES ON HISTORICAL SOCRATES

ABSTRACT: This paper discusses the Socrates' approach by Gregory Vlastos in "The historical Socrates and Athenian Democracy", published in the journal Political Theory (1983), and its impact.

KEYWORDS: Gregory Vlastos; Socrates; Greek Democracy.

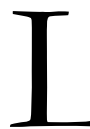

as investigaciones de Gregory Vlastos, como se sabe, se centran en Sócrates sobre todo a partir de 1976, hasta la publicación de su artículo "Sócrates, ironista y filósofo moral", en 1991, que ha inspirado todo un capítulo del libro The Art of Living de Alexander Nehamas (2000), donde este último discute la interpretación de Vlastos en torno a la ironía socrática, un tema relevante del que se han ocupado varios de los participantes en el coloquio "Tradición y ruptura: los clásicos en la obra de G. Vlastos". Michael Frede comenta que en opinión de Vlastos Sócrates sostuvo una posición filosófica que es posible rastrear en los primeros escritos de Platón (Michael Frefe, en Gómez-Lobo, 1999: 20). Para los propósitos de este trabajo, me concentraré en un artículo de Vlastos publicado en 1983: "The historical Socrates and Athenian Democracy", en la revista Political Theory v. 11, n. 4 (nov., 1983) y tendré en cuanta también el debate suscitado por este texto.

Gregory Vlastos aclara en la primera nota de su artículo que se trata de un "trabajo en proceso" e inacabado, y admite que no ha dado respuesta en él a varias críticas y comentarios recibidos a una versión anterior, presentada en febrero de 1983 en la Universidad de Londres; agradece de nueva cuenta la discusión y las críticas de varios colegas presentes en dicha ocasión. Lo anterior podría verse como una
* Una primera

versión de este

artículo fue

presentada en forma

de ponencia en el

Coloquio Tradição e

Ruptura: os Clássicos e a obra de Gregory

Vlastos, organizado por el Núcleo de Estudos Antigos e Medievais (NEAM)

de la Universidade

Federal de Minas

Gerais, Belo

Horizonte, el 30 de mayo de 2011.

** Departamento de Filosofía, Universidad Autónoma de

México I. 
mera salida estratégica, una excusa retórica a sus críticos y una manera de prevenir nuevas críticas, sin embargo, no es el único caso en que él mismo atribuye o reconoce el carácter inacabado de sus propios escritos. Se trata de un estilo de escritura, una forma de trabajar y de entender la actividad filosófica, que me parecen dignas de destacar y elogiar en el contexto de un homenaje a su trabajo, en particular, al estilo argumentativo y dialéctico de sus trabajos.

Su estilo de escritura filosófica se distingue por el vigor argumentativo y polémico. Adopta una forma de expresión clara, directa, muy concisa y elocuente, que combina la agudeza del análisis conceptual con la agilidad y la solidez lógica, un conjunto de cualidades que muestran la brillantez del autor. Sus textos son un raro equilibrio entre la inteligencia, la erudición y la discusión filosófica. A juicio de algunos especialistas, Vlastos se enfoca en las cuestiones que juzga relevantes desde el punto de vista analítico y filosófico, pero deja de lado aspectos de orden literario propios de la escritura platónica, sumamente significativos y ricos, en una línea opuesta en este punto a la lectura de Luc Brisson, quien aprecia y valora no sólo el aspecto argumentativo y conceptual de los diálogos platónicos, sino que atiende también a los detalles dramáticos y los giros lingüísticos. Nada más alejado de la perspectiva analítica de Vlastos que la apreciación poética del pensamiento, a la manera de George Steiner (2012). No se trata de una simple repulsa de lo literario o de lo poético, y de todo aquello que forma parte de las circunstancias particulares del contexto histórico y cultural, sino de toda una manera de entender a la filosofía y su tarea conceptual, argumentativa y crítica.

Vlastos dialoga siempre con las fuentes directas tanto como con los intérpretes y los estudiosos de la antigüedad y de su propio tiempo, y no se contenta con presentar su propia lectura ni exponer sus propias tesis, de manera escueta, sino que adopta un estilo riguroso y dialéctico. Este aspecto de su método me parece sumamente valioso, desde el punto de vista filosófico, al igual que su apertura a las críticas y el modo en que él mismo las formula y en que replica a sus críticos; un estilo próximo al socrático, que concede genuina atención a los argumentos opuestos y que mantiene una disposición a reexaminar a fondo su propia posición, corregirla o modificarla, si es preciso.

En el artículo dedicado a la relación de Sócrates y la democracia ateniense, Gregory Vlastos examina con cuidado y sopesa la validez de la interpretación más aceptada en su momento acerca de la relación de Sócrates con la democracia ateniense, tratando de llegar a la mejor respuesta a las preguntas y los problemas en torno a esta cuestión, a la luz de las distintas posibilidades lógicas, en un sano ejercicio dialéctico, de inspiración socrática, que es pertinente retomar. El autor se muestra dispuesto a revisar a fondo sus propios puntos de vista a la luz de los argumentos contrarios y a corregir y modificar sus anteriores juicios y opiniones, lo cual es una muestra palpable del talante filosófico de su forma de trabajar. Por eso me parece, además de un excelente platonista e historiador de la filosofía antigua, un agudo filósofo capaz de traer al presente los antiguos debates e iluminarlos con una nueva luz. Es ante todo un maestro capaz de hacernos comprender y apreciar la contemporaneidad de los clásicos.

En "El Sócrates histórico y la democracia ateniense", Vlastos argumenta a favor de dos tesis: 1) que Sócrates fue percibido en su tiempo y en Atenas como un sofista subversivo 
y que esta percepción por parte de sus conciudadanos tuvo un peso decisivo en su juicio y condena por los cargos que formalmente se le imputaron, y 2) que dicha percepción pública fue errónea y que Sócrates no fue el cripto-oligarca que sus jueces pensaron que era.

Lo primero que se propone Vlastos es entender la relación del Sócrates histórico con su ciudad, a partir del examen de diversas fuentes disponibles que considera sólidas y adecuadas para considerar los puntos que se propone tratar, sin limitarse a elegir, como suele hacerse, entre los principales testimonios disponibles (los de Jenofonte, Aristófanes o Platón), y a partir de tal elección, proceder a defender su propia posición. En suma, a diferencia de otros especialistas, Vlastos considera las tres fuentes principales para aproximarnos al Sócrates histórico y toma además en cuenta algunas otras fuentes tardías para apoyar sus argumentos, apartándose con ello de la senda seguida por buena parte de los estudiosos.

En un afán que pareciera en ciertos momentos exagerado y un tanto extravagante, por encontrar nuevas evidencias y agregar más elementos de juicio, acude a algunas otras fuentes documentales para sostener la tesis que él propone, dándole un nuevo sesgo o giro, e introduce un matiz para examinar y comprender la cuestión que le interesa plantear. Su enfoque, más analítico que histórico, se centra sobre todo en los argumentos y prescinde relativamente del contexto cultural e histórico, el cual figura de manera indirecta y secundaria en su análisis y línea de argumentación. Un aspecto que ha sido justamente cuestionado por varios de sus críticos.

Su estilo de escritura reformula los problemas y las tesis, y los expone en forma condensada y directa. Plantea las cuestiones, las comenta y discute en unos términos que quizá algunos juzguen anacrónicos y en ocasiones poco ajustados a la letra, a pesar de que él justifique la elección de ciertos términos en vez de otros a la hora de ofrecer cierta traducción (por ejemplo, del término heirou (literalmente 'elección') por “preferencia”, en determinado contexto) porque en su opinión nos permiten comprender las cuestiones que se debaten en un sentido quizá más próximo y actual. Puede decirse que, en general, su enfoque se dirige a recuperar la dimensión estrictamente argumentativa de la obra de Platón, prescindiendo de aspectos literarios y de cualquier otra dimensión del texto que no sea de naturaleza estrictamente argumental. Un método que algunos han juzgado un tanto reduccionista y estrecho.

No me ocuparé aquí del problema de qué tan apropiado es el procedimiento metodológico seguido por Vlastos en sus comentarios y análisis, en lo que respecta a la decisión de deja de lado numerosos aspectos de la obra de Platón referentes al contexto de la discusión en el seno mismo de la obra y a los aspectos tocantes al contexto de la discusión en un sentido más amplio, que atañen al momento histórico y cultural, todos los cuales son considerados por otros intérpretes con mucha atención y sumo cuidado, porque nos aportan elementos adicionales para la comprensión adecuada de la discusión filosófica y sus propios alcances. Me refiero a una variedad de contenidos, asuntos y detalles, que Vlastos y otros estudiosos juzgan filosóficamente irrelevantes, pero que a la luz de otras aproximaciones a los diálogos platónicos cobran sentido y relevancia, no sólo poética y cultural sino filosófica. Me refiero a un conjunto de elementos de las obras que Vlastos considera prescindibles 
y que él decide ignorar, pero que a los ojos de otros estudiosos nos aportan elementos hermenéuticos suplementarios para la comprensión apropiada de la discusión filosófica y su alcance. Este punto merecería sin duda un examen detallado y un espacio más amplio que el permitido por este espacio. Baste señalar que detrás del método analítico de Vlastos pareciera estar la convicción filosófica de que sería cuestionable, desde el punto de vista lógico, pretender iluminar el sentido de la obra de Platón y aproximarnos en particular a la figura del Sócrates histórico a partir de consideraciones “externas", tocantes al contexto de su tiempo y su cultura o su horizonte original, en lugar de considerar y sopesar directamente los argumentos presentes en las obras mismas. De ahí, tal vez, que su análisis se centre casi por completo y de manera exclusiva en las fuentes documentales y testimoniales y relegue aspectos de la época y el contexto cultural a los que otros especialistas les conceden peso para dirimir la cuestión de cuál fue la posición política del Sócrates histórico. (cf. Ellen M. Wood y Neal Wood, 1986)

Así, Vlastos comienza por citar unas líneas del discurso de Esquines, Contra Timarco, 173, que hacen referencia a Sócrates como sofista y educador de Critias, uno de los treinta tiranos. Vlastos remarca que se trata de una fuente que data medio siglo después de la muerte de Sócrates, y que lo asocia a una de las figuras más destacadas del régimen político más antidemocrático de la antigüedad. En relación con este punto y para subrayar el peso atribuido al influjo de la enseñanza musical sofística apunta el caso de Pericles, quien fuera educado por Damón (Plutarco, Pericles 4, 1; Aristóteles, Cri. 53b7-c3). Su argumento es que si en la mente del auditorio de Esquines y de Plutarco estaba todavía presente la idea del enorme influjo de la educación sofística en la trayectoria política de personajes relevantes de la política ateniense, como Pericles y Critias, cabe inferir que, en tiempos de Sócrates, esta idea debió pesar todavía más y Sócrates debió seguramente aparecer a los ojos de sus conciudadanos como el instigador de Critias, y algo similar pudo ocurrir también en el caso de Alcibíades, otro personaje muy controvertido de la política ateniense. Al respecto, cita a Jenofonte, Mem. 1, 2, 12: "Pero el acusador dijo que Critias y Alcibíades, habiéndose asociado con Sócrates, hicieron gran mal a la ciudad” (apud. Vlastos, 1983: 496).

Vlastos pretende basar su propio juicio acerca del Sócrates histórico en una inferencia bien fundada y no meramente en alguno de los testimonios, específicamente el de Jenofonte en las Memorias de Sócrates, que tendió a privilegiarse desde el siglo XVIII (Burnet, 1991: 38), de manera que ofrece un argumento adicional apoyado en dos fuentes tardías para reforzar, más que "confirmar", como él pretende, ${ }^{1}$ la tesis de que Sócrates fue percibido en su tiempo como un sofista instigador y subversivo, aunque esta imputación no apareciera formulada de manera directa ni expresa en la acusación formal.

Quisiera subrayar que el argumento aducido por Vlastos a favor de lo anterior refuerza más que confirma su inferencia, aunque el propio Vlastos considere que dicha inferencia queda confirmada en el texto 4 de su artículo (496-497):

\footnotetext{
${ }^{1}$ De hecho, Vlastos mismo admite que "es una inferencia razonable que lo mismo pudo ser verdadero en tiempos de Sócrates".
} 
Jenofonte, Mem. 1, 2, 9: "Pero, por Zeus, dijo el acusador, él hizo a sus asociados despreciar las leyes establecidas, diciendo que era tonto elegir a los magistrados de la ciudad por sorteo, cuando uno no querría servirse de un piloto seleccionado por sorteo o un constructor o un flautista o a ningún otro (artesano) para trabajar en aquello en lo que los errores son bastante menos desastrosos que aquellos que conciernen a la ciudad".

La estrategia argumentativa de Vlastos presenta como una confirmación de lapropia inferencia, las líneas recién citadas de las Memorias de Sócrates, de Jenofonte. La inferencia es razonable y plausible, y la línea de argumentación y el modo en que él expone y construye su argumento generan en el lector la impresión de que en efecto él no se ha limitado simplemente a concederle crédito al testimonio de un amigo de Sócrates y a aceptarlo como una evidencia.

A partir de la Apología platónica, donde se menciona que Sócrates se atrajo fuertes enemistades y se alude al hecho de que el retrato aristofánico fue tenido por verdadero, Vlastos considera, a diferencia de J. Burnet, que las acusaciones formales contra Sócrates no se limitaron a ser "meros pretextos". En apoyo de lo anterior, construye un argumento coherente y sólido basado en las principales fuentes disponibles. Quizá la mayor originalidad de su línea de argumentación estribe en que dichas fuentes ofrecen testimonios muy dispares sobre el Sócrates histórico, percepciones distintas y difíciles de conciliar entre sí en muchos puntos, que inclusive se tienen, en general, como testimonios excluyentes, y que, no obstante, Vlastos logra hacerlos embonar entre sí, para ofrecernos una visión coherente de cómo fue percibido el Sócrates histórico por sus conciudadanos.

A su juicio, la única acusación politica en contra de Sócrates fue la de corromper a los jóvenes (497). Esta apreciación es discutible, pero no voy a ocuparme ahora de este punto para no desviarme de la línea de argumentación de Vlastos ni distraer la atención del lector. Por el momento, me concentraré en algunos otros aspectos de su análisis de cómo fue percibido Sócrates en su tiempo por sus conciudadanos.

Aunque Vlastos admite que la acusación formal no hace referencia explícita a la imputación de subversión (497), aduce que su vínculo tutorial con Critias y otros líderes oligarcas pudo ser visto por los atenienses con recelo y como una violación a la ley de amnistía, de modo que Sócrates pudo haber sido solamente acusado por cargos no totalmente políticos, como no creer en los dioses "del estado" e introducir nuevas divinidades, o sólo indirectamente políticos, como corromper a los jóvenes (497). Me parece un tanto discutible la apreciación de Vlastos acerca de la naturaleza de las acusaciones imputadas a Sócrates.

En particular, me detendré en la fórmula "religión de estado" utilizada por Vlastos para referirse a la acusación de impiedad (asébeia), ya que le atribuye un sentido a la acusación que no corresponde en rigor a la religión griega ni a su lugar en la cultura, en la Atenas de la era clásica, pues la piedad religiosa formaba parte de un deber cívico y la prohibición de la impiedad y las penas en contra de ella, dictadas en Atenas por instigación de Diopites durante el gobierno de Pericles, protegían las antiguas creencias y las prácticas religiosas en un sentido conservador. Para la mayoría de los atenienses, el respeto a las leyes contra la 
impiedad se refería no a "dioses del estado", sino a los dioses de la ciudad, es decir, los dioses de la comunidad, de manera que las implicaciones y las consecuencias derivadas de cualquier infracción en dicha materia poseían para la mayoría de los atenienses unos alcances muy distintos a los sugeridos por expresiones tales como "dioses del estado" o "religión de estado", utilizadas en forma indistinta e intercambiable por Vlastos, ya que los atenienses en general concebían que el destino mismo de la polis se vería gravemente comprometido en el caso de una infracción religiosa de esa naturaleza.

Un ejemplo claro del sentir popular en esa materia fue la reacción popular a la profanación de los Hermes - el llamado "escándalo de los Hermes", ocurrido en vísperas de la expedición a Sicilia, en el cual se vio envuelto Alcibíades (Tucídides VI, 27-29). Es claro que la reacción ateniense ante ese suceso no corresponde a lo que pudiera catalogarse una respuesta popular a un acto infractor de una mera "religión de estado". Es importante reparar en esto y advertir el profundo contraste entre las creencias religiosas compartidas por una comunidad, arraigadas de manera muy honda en su propia tradición, y las convicciones o los preceptos de una "religión de estado", de lo contrario sería difícil explicar la gravedad atribuida a la impiedad y el castigo tan severo que las leyes atenienses estipulaban a su infractor, la pena de muerte. Para los atenienses se trataba de un delito político grave y consideraban que atentaba contra la propia comunidad.

En cuanto a la conjetura de Vlastos de que Sócrates pudo haber sido visto como "un infractor de la ley de amnistía" (497), es claro que varios de los argumentos de Sócrates tanto en la Apología como en Critón, hacen referencia a que él pudo haberse acogido a dicha ley y abandonar en su momento la ciudad, ${ }^{2}$ como muchos otros ciudadanos disidentes, y si no lo hizo fue por causa de su amor a Atenas y su preferencia por las leyes atenienses, por tanto, hay ciertas bases para inferir que algunos de sus conciudadanos lo hayan visto con suspicacia, pero carecemos de evidencias de que un sector de los atenienses tuviese dicha sospecha específica contra él, ya que no aparece expuesta de manera explícita y carecemos de indicios claros de ello, aunque no podamos descartar la posibilidad apuntada por Vlastos. $\mathrm{Al}$ margen de lo anterior, me parece que es innecesario suponer que Sócrates haya sido visto como un posible infractor de la ley de amnistía, como conjetura Vlastos, para comprender el cariz netamente político de las acusaciones de las que fue objeto, y para admitir que Sócrates fue visto como un impío especulador y como un retórico tramposo, un pro-oligarca que fomentaba esa clase de sentimientos entre sus amigos (497). Lo anterior es algo que prácticamente nadie se atrevería a poner en cuestión, por lo cual pareciera un tanto ociosa toda esa elaborada construcción argumental a partir de una suposición suplementaria, pero prescindible e innecesaria a fin de cuentas, para entender el sentido de las graves acusaciones por las que Sócrates fue llevado ante el tribunal y fue condenado, aun cuando Platón se empeñe en presentar dicha condena como un castigo que Sócrates pudo haber evitado si

\footnotetext{
${ }^{2}$ Ellen y Neal Wood, cuando hacen referencia a este punto en su réplica a Vlastos, ponen el énfasis en el hecho de que Sócrates permaneció en la ciudad durante el gobierno oligárquico y tiránico de los cuatrocientos. Más adelante me referiré a este punto.
} 
hubiese aceptado la pena del pago de una multa, y si no hubiese exasperado con su ironía a los jueces.

Revisemos ahora la segunda tesis defendida por Vlastos en su artículo "Sócrates y la democracia ateniense": Sócrates fue percibido como un ideólogo pro-oligárquico que alentaba la hostilidad hacia la constitución ateniense y esta percepción fue completamente falsa. Vlastos toma como base el Critón de Platón (Critón 51c4-53c8), donde es clara la preferencia socrática por la constitución ateniense. Concuerda, así, con la opinión de George Grote de que "es una pieza de retórica imbuida del más genuino espíritu de democracia constitucional", en la cual "Sócrates hace expresos sus sentimientos y repite el lenguaje de un devoto patriota democrático" (apud., 498).

En opinión de Vlastos, el pasaje de la prosopopeya de las leyes debe ser leído de diferente manera a como suele ser leído por muchos estudiosos, y comenta que Sócrates expresa su amor por la ciudad de Atenas, y en seguida, justifica su propia traducción del término heirou (literalmente "elección') por "preferencia", a partir del contexto - "(la elección a favor de las leyes de Atenas (bemas heirou) es bosquejada a lo largo del pasaje como expresando una preferencia por sus leyes por encima de otras ciudades)-, de manera que el adverbio cualificativo (no elegido per se, sino preferencia), introduce un matiz y la intensidad expresada en dicho pasaje" (499). Aparentemente, Vlastos juzga que una elección sería algo más "neutral" que una preferencia, dado que esta última alude según el propio parecer de Vlastos a una inclinación más íntima o personal. Los Wood censurarán con dureza esta traducción, por considerarla sesgada, a pesar de que en rigor no violenta el sentido del texto. Por lo demás, para muchos de nosotros resulta dudosa la pretendida "diferencia de matiz" entre los términos 'elegir' y 'preferir', apuntada por Vlastos para justificar su propia traducción.

Al final del pasaje del Critón 52b1-c1, Sócrates pronuncia las siguientes palabras: “ $\mathrm{i} . .$. a quién podría gustar una ciudad sin las leyes?" (499). Vlastos plantea que a pesar de que en dicho pasaje no se mencionen las leyes de la ciudad de Atenas, ni las de la democracia o de la oligarquía, no cabe duda de que "la preferencia socrática por las leyes atenienses es una preferencia por la constitución democrática" (499). Lo curioso es que se siente obligado a fundamentar este juicio con el argumento de que Sócrates preferiría a su ciudada natal, Atenas, por encima de las cuatro oligarquías bien gobernadas, donde se respetaban las leyes -Esparta, Creta, Tebas y Megara-, a pesar del testimonio de Apología 31d, donde Sócrates declara que difícilmente un hombre podría sobrevivir si se opusiera a la multitud, tratando de evitar que se cometieran en la ciudad las múltiples injusticias e ilegalidades que se cometían.

Vlastos admite que las diversas críticas formuladas por Sócrates a la democracia ateniense y a sus líderes bastaban para considerarlo un enemigo de la democracia, ${ }^{3}$ y no un mero conservador al estilo de Isócrates, quien en Aerop. 37 señala que él mismo corre el riesgo de ser tenido como un enemigo del pueblo (misódemos) y de pretender el retorno de la

\footnotetext{
${ }^{3}$ Por ejemplo, el hecho de que señalara que un hombre justo resuelto a luchar por la justicia virtualmente signaría su muerte (500) y que en el Gorgias Sócrates ataque duramente al liderazgo ateniense y remarque que la adulación es un boleto para conseguir el poder del demos, o que haya señalado que cuatro de los principales líderes atenienses: Temístocles, Milcíades, Cimón y Pericles, fueron serviles demagogos.
} 
oligarquía. Su artículo destaca la tónica de la mentalidad de la época para hacer ver el peso de la percepción popular en el juicio y la condena de Sócrates y defiende que los ataques socráticos a ciertas prácticas políticas comunes en su tiempo y sus críticas, no son inconsistentes con su preferencia por su ciudad y sus leyes, como algunos parecen suponer (501-502). Lo cual es correcto, me parece. Vlastos puntualiza con mucha razón que Sócrates atribuye su propia condena no a una falla de las leyes de su ciudad, sino a un error de los jueces.

El testimonio del Critón le parece a Vlastos apartado de las opiniones de J. Burnet, quien considera a Sócrates un "irreconciliable opositor de la democracia de Pericles" (apud., 502), de Heinrich Maier, para quien Sócrates pensaba que "la democracia era la más perversa de todas las formas de gobierno (apud., 502), y también de Guthrie, para quien Sócrates sostuvo puntos de vista "que contravenían las bases de la democracia griega" (apud., 502), y argumenta que tendríamos que hacer algo así en oposición al testimonio de Platón. Para Vlastos, tendríamos que atender, para sustentar tales puntos de vista, exclusivamente el testimonio de Jenofonte en Mem. 3, 9, 10:

Él dice que los reyes y quienes gobiernan no son quienes tienen el
cetro, ni quienes son elegidos por azar, por la mayoría, ni por quienes
deben su poder a la fuerza o por astucia; sino quienes saben cómo
gobernar. Si se conviene en que es propio del gobernante ordenar y
del gobernado obedecer, hacía ver que quien gobierna un barco es
quien sabe cómo gobernarlo, mientras que el propietario del barco
y todos los otros a bordo obedecen a quien sabe [y es así en el caso
de la agricultura, el tratamiento de la salud, el entrenamiento físico:
quienes tienen el conocimiento gobiernan].

El conocimiento al que aluden las líneas citadas, es el arte de gobernar, sobre el cual no parece decir mucho Sócrates, excepto que es la base de la autoridad política. $\mathrm{Al}$ respecto, Vlastos cita estas palabras de Jenofonte en Mem. 3, 2, 4: "Cuando Sócrates inquiría cuál es la virtud del buen gobernante, él dejaba fuera todo excepto esto: procurar la felicidad de sus gobernados". De acuerdo con Jenofonte, Sócrates consideraba entre los elementos de la felicidad cívica: la riqueza material, la supremacía militar, las buenas relaciones con otras ciudades, las relaciones armoniosas entre los ciudadanos mismos, por lo cual consideraba que el gobernante debía poseer un conocimiento sólido sobre las finanzas públicas, la ciencia militar, la diplomacia y de "retórica de la amistad cívica" (503). Esta peculiar formulación de las artes propias del buen gobernante omite de manera extraña el arte de legislar, un arte imprescindible para un buen gobierno. Es interesante observar que Sócrates formulara su idea del arte de gobernar en términos técnicos y que considerara que su finalidad propia era procurar la felicidad de los gobernados. Una idea próxima a la de algunos sofistas, que exigía un conjunto de saberes y prácticas necesarios para alcanzar y asegurar la paz y el bienestar de la comunidad.

La tesis socrática de que el conocimiento es un requisito necesario y una condición sine qua non para gobernar bien, chocaba desde luego con una de las más distintivas instituciones de la democracia ateniense, la elección por sorteo. Al respecto, Vlastos señala que "uno 
podría tratar de eliminar la ofensa de la democracia al 'arte de gobernar' con el argumento de que los elegidos por tal recurso fueron los magistrados, los oficiales subordinados de la administración. Pero esto podría pasar por alto el hecho de que no solamente ellos fueron electos por sorteo, ya que los miembros del Consejo, el pro-boulético y el comité ejecutivo de la Asamblea soberana, fueron elegidos también con ese mismo procedimiento, al igual que los miembros del dikastério, cuya suprema autoridad judicial estaba a la par que la autoridad de la Asamblea soberana. A excepción del cargo de general, la magistratura ejecutiva más importante, que era elegida por voto directo en la asamblea, como en las oligarquías. A los ojos del Sócrates de Jenofonte, éste procedimiento podría ser redimible, — pero no suficientemente redimible, dada su baja opinión del nivel intelectual del electorado democrático" (504). La apreciación socrática pudo ser demasiado pesimista y exagerada, teniendo en cuenta que el régimen democrático, carente de una burocracia administrativa, proveyó a los ciudadanos atenienses, en la práctica, gracias a la participación política activa y el ejercicio cívico de las distintas magistraturas, una experiencia y una capacitación política suficiente, sin la cual difícilmente se podría haberse mantenido el régimen democrático por cerca de doscientos años en Atenas.

La democracia ateniense extendió los derechos ciudadanos a los bánausoi, la población masculina asalariada dedicada a tareas productivas necesarias. En tanto que las ciudades oligárquicas tuvieron un régimen de ciudadanía más restringido. Algunas opiniones de Sócrates lo ubicarían a los ojos de muchos como pro-oligarca, considerando su tesis del arte de gobernar, el cual estipula que debe gobernar "el más inteligente y capaz". No obstante, Vlastos sostiene la opinión de que "en los escritos socráticos de Jenofonte, por un lado, y los diálogos socráticos de Platón, por otro, encontramos dos filósofos cuyos sentimientos políticos son diametralmente opuestos" (505). El Sócrates de Jenofonte muestra una clara preferencia por la oligarquía, mientras que el Sócrates platónico (específicamente el del Critón) prefiere la democracia ateniense, la más extrema, por encima de las oligarquías mejor gobernadas de su tiempo, a pesar de sus duras críticas a la ilegalidad y la conducta injusta que prevalecían en su ciudad de origen (506). Ésta será la opinión que Ellen y Neal Wood cuestionarán con más ahínco en su dura réplica a Vlastos.

Cuando los Wood cuestionan la interpretación de Vlastos, ponen mucho énfasis en el hecho de que Sócrates permaneció en la ciudad durante el gobierno oligárquico y tiránico de los cuatrocientos. Sin embargo, no parecen reparar ambos críticos en que el texto citado por Vlastos hace referencia a otra circunstancia posterior, no a ese momento específico, sino al momento de la reinstauración de la democracia, en que se dictó la ley de amnistía para quienes no hubieren participado en los actos del régimen de los treinta tiranos y se permitió el exilio voluntario. La asamblea concedió un plazo para el registro de los ciudadanos que voluntariamente decidieran abandonar la ciudad; algunos atenienses eligieron emigrar a Eleusis y conservaron sus derechos civiles y sus propiedades (AP 39 1), y las restricciones para los ciudadanos residentes en Eleusis fueron que no podrían ejercer cargos, en tanto no fuesen registrados de nuevo como residentes en Atenas. El acuerdo popular fue entonces que "nadie podría pedir represalias contra nadie por los acontecimientos pasados, salvo contra 
los Treinta, los Diez y los Once y los que habían gobernado en el Pireo. Tampoco podrían pedirse contra estos si rendían cuentas" (AP 39 6). Todo ello dirigido a conseguir el cese de las hostilidades y a evitar más enfrentamientos entre los ciudadanos.

Es claro que Sócrates no se acogió a tal ley y no escogió el exilio voluntario, y que él mismo apela a ese hecho como una prueba de su acuerdo con el régimen democrático. Los Wood, sin embargo, restan peso a dicho argumento a partir de que Sócrates, en lugar de abandonar su ciudad natal, permaneció en ella durante la tiranía, con lo cual juzgan que puso de manifiesto su simpatía por dicho régimen, y desconocen los argumentos aducidos por Sócrates en la Apología. No obstante, cabe suponer que Sócrates no haya previsto ni calculado en el momento de la instauración del régimen de los treinta que éste terminaría siendo un tipo de gobierno criminal, y es posible que él esperara que, luego de cierto tiempo, algunas de las medidas tomadas inicialmente a causa de la crisis ocasionada por la derrota militar ateniense pudieran modificarse posteriormente, y que de manera gradual la ciudad lograría recuperarse e incluso mejorar respecto al gobierno democrático anterior, al que Sócrates dirigió tan severas críticas. Lo cierto es que Vlastos no se detiene en esta clase de cuestiones históricas y un tanto hipotéticas, y se concentra tan solo en el análisis de los argumentos.

El principal argumento de Vlastos contra la apreciación de Sócrates como un cripto-oligarca es que la doctrina socrática del arte de gobernar no encierra las implicaciones anti-democráticas que para algunos entraña, puesto que en principio la virtud moral, el perfeccionamiento del alma y la felicidad serían los mismos para todos (Gorgias 470 e8-11):

Can we imagine what a transvaluation of values this Socrates -Plato's, not Xenophon's- presses on his World in telling an upper class Athenian that the criterion of his statesmanship is whether or not it improves the souls of the people of Athens -even the souls of slaves? (507)

Para los Wood, la tesis de Vlastos resulta por completo implausible, y ambos plantean que la concepción socrática del "royal are" ("el arte de gobernar") estuvo impregnada de los valores aristocráticos y resultaba en el fondo oligárquica, partiendo principalmente del testimonio de Jenofonte y restándole peso a la exposición platónica, más filosófica. En realidad los Wood no se apoyan de manera directa en los argumentos expuestos en los diálogos socráticos, sino que parten de consideraciones presuntamente históricas y de apreciaciones en torno al contexto cultural, como he puesto de manifiesto un poco antes en relación con la cuestión del exilio, y le restan peso a los argumentos esgrimidos por Vlastos, para quien a la luz del Menón, es evidente que la sabiduría moral, según el Sócrates platónico, no podía ser monopolizada por un sector de la ciudad ni pertenecer a unos cuantos, sino que todos podrían en principio ser llevados a perfeccionar su alma y hacer de lo anterior su supremo fin (tanto extranjeros como ciudadanos, esclavos y hombres libres, mujeres y varones) (508).

Vlastos formula su tesis de que la visión de Sócrates como un cripto-oligarca es falsa, a partir de la evidencia positiva que, a juicio suyo, proporciona el Critón, si bien admite que Sócrates no aporta una teoría para justificar su preferencia. Según él, se muestra como un demotikós, esto es, un philódemos, en lugar de un misódemos o enemigo del pueblo. 
Es en esta parte de su artículo en donde Vlastos se adhiere a la imagen de Sócrates de los diálogos socráticos de Platón: todos podemos poseer el "arte de gobernar", cada uno de nosotros puede vivir una vida examinada, regir la propia vida por el conocimiento personal y la visión del bien. Mientras que los Wood ponen en cuestión esta tesis, a partir de las opiniones socráticas transmitidas por Jenofonte.

De acuerdo con los diálogos tempranos de Platón, Sócrates critica de manera abierta las fallas de la vida pública ateniense y ataca el pago por los oficios públicos, cuyos efectos considera corruptores, pero nunca ataca ninguna otra institución ateniense ni dice una palabra en contra de la elección por sorteo, tampoco declara ni implica que el conocimiento del arte de gobernar (statecraft) sea una condición de la legítima autoridad cívica (510-511). Y a continuación aduce varias razones para creer que Sócrates prefirió la democracia a la oligarquía:

1) su relación con Querefón, un reconocido partidario de la democracia, y en apoyo de lo anterior cita la Apología y las Nubes, donde Aristófanes lo ubica como un igual a Sócrates en el Pensadero.

2) la admiración de Lisias, quien lo conoció bien y escribió una Apología (scol. Por Arethas en Platón, Apol. 18b), probablemente como réplica a la Acusación publicada de Polícrates.

Los testimonios sobre Sócrates permiten conjeturar que él fue lo bastante irónico y lo suficientemente ambiguo para dar lugar a opiniones muy encontradas acerca de sus propias ideas y para no complacer a ninguno de los bandos. Es posible que su profesión de ignorancia y su negativa a asumir una posición clara y definitiva sobre las cuestiones debatidas, aunadas al hecho de que él se haya atrevido a exponer de manera abierta y directa las ideas más contrarias a las opiniones compartidas y al status quo, suscitaran en sus interlocutores y contemporáneos no sólo opiniones tan encontradas acerca de sus propias preferencias políticas, sino la impresión de que era un acérrimo opositor del régimen democrático.

Vlastos mismo admite que los dos últimos indicios que él toma como base para sostener que fue errada la percepción de Sócrates como un cripto-oligarca enemigo de la democracia (su amistad con Querefón y el respeto y la admiración de Lisias) constituyen "briznas de inferencia" (wisps of inference), pero que nos dan, a su juicio, "razones para creer que amigos de Sócrates, quienes apostaron sus vidas y fortunas en la democracia ateniense de su tiempo, cuando su supervivencia pendía de una amenaza, sintieron que Sócrates estaba de su lado" (512).

¿Por qué restar peso a esta posibilidad y conceder mayor peso a la posibilidad contraria? El argumento de los Wood a favor del Sócrates pro-oligárquico no toma en cuenta las fuertes críticas de Sócrates al linaje, el género y la riqueza como fundamentos de la autoridad política, expuestos en los diálogos platónicos tempranos. Para el Sócrates platónico, en efecto, el único requisito válido para gobernar bien era la excelencia, entendida como sabiduría moral, de manera que los argumentos aducidos por Vlastos merecen ser tenidos en cuenta. 


\section{REFERÊNCIAS}

ARISTÓTELES. La constitución de los atenienses. Edición bilingüe. Trad. A. Bernabé Pajares. Madrid: ABADA Editores, 2005.

BURNET, J. La vida de Sócrates. In: HUSSEY, E., BURNET, J., VLASTOS, G. Los sofistas y Sócrates. Selección y nota preliminar de Alberto Vargas. México: Universidad Autónoma Metropolitana, 1991. pp. 37-66.

GÓMEZ-LOBO, A. La ética de Sócrates. Trad. Andrea Palet, prefacio de Michael Frede. Santiago de Chile: Ed. Andrés Bello, 1999.

NEHAMAS, A. The Art of Living: Socratic Reflections from Plato to Foucault. Berkeley: University of California Press, 2000.

RHODES, P. J. A Commentary on the Aristotelian Athenaion Politeia. Oxford: Clarendon Press, 1993.

STEINER, George. La poesía delpensamiento: Del helenismo a Celan. Trad. María Condor. México: FCE/Siruela, 2012.

TUCÍDIDES. Historia de la guerra del Peloponeso. Trad. y notas J. J. Torres Esbarranch. Madrid: Gredos, 1992.

VLASTOS, G. The historical Socrates and Athenian Democracy. Political Theory, v. 11, n. 4, p. 495-516, nov., 1983.

WOOD, Ellen M., WOOD, Neal. Socrates and Democracy: A Reply to Gregory Vlastos. Political Theory, v. 14, n. 1, p. 55-82, febrero, 1986. 